\title{
(2) OPEN ACCESS \\ Low fraction of fetal haemoglobin is associated with retinopathy of prematurity in the very preterm infant
}

\author{
William Hellström (D) , ${ }^{1}$ Tobias Martinsson, ${ }^{2}$ Eva Morsing, ${ }^{2}$ Lotta Gränse (D) , \\ David Ley, ${ }^{2}$ Ann Hellström (1) ${ }^{4}$
}

1 Department of Pediatrics, Institute of Clinical Sciences, Sahlgrenska Academy, University of Gothenburg, Gothenburg, Sweden

${ }^{2}$ Department of Pediatrics, Institute of Clinical Sciences, Skåne University Hospital Lund, Lund, Skåne, Sweden

${ }^{3}$ Department of Clinical Sciences, Ophthalmology, Skåne University Hospital Lund, Lund, Sweden

${ }^{4}$ The Sahlgrenska Centre for Pediatric Ophthalmology Research, Department of Clinical Neuroscience, Institute of Neuroscience and Physiology, Sahlgrenska Academy, University of Gothenburg, Gothenburg, Sweden

Correspondence to Dr William Hellström, Department of Pediatrics, Institute of Clinical Sciences, Sahlgrenska Academy, University of Gothenburg, Gothenburg 416 85, Sweden; william.hellstrom@gu.se

Received 30 October 2020 Revised 8 January 2021 Accepted 20 January 2021

\section{ABSTRACT}

Background Blood loss and adult blood transfusions are common during the neonatal period in preterm infants. The objective of the study was to clarify if degree of loss of fetal haemoglobin ( $\mathrm{HbF}$ ) was associated with later retinopathy of prematurity (ROP).

Methods Retrospective observational cohort study. In total, 452 infants born $<30$ gestational weeks at a tertiary level neonatal intensive care unit in Sweden in 2009-2015 were included, 385 of whom had final ROP outcome. Mean fractions of $\mathrm{HbF}(\%)$ during the first postnatal week were calculated from 11861 arterial blood gas analyses. The relationship between fractions of $\mathrm{HbF}(\%)$ and ROP was evaluated.

Results The mean (SD) gestational age (GA) at birth was 26.4 (1.8) weeks. In total, 104 (27\%) infants developed ROP. Higher fraction of $\mathrm{HbF}(\%)$ was associated with a lower prevalence of ROP, OR by a $10 \%$ increase 0.83 (95\% Cl: 0.71 to $0.97 ; p=0.019$ ), following adjustment for $\mathrm{GA}$ at birth, small for GA and sex. Infants with $\mathrm{HbF}(\%)$ in the lowest quartile had OR of 22.0 (95\% Cl: 8.1 to $59.2 ; p<0.001)$ for ROP development compared with those in the highest quartile. The predictive ability (area under the curve) of $\mathrm{HbF}(\%)$ in the full model during the first week was 0.849 for ROP.

Conclusions Early low fraction of $\mathrm{HbF}$ is independently associated with abnormal retinal neurovascular development in the very preterm infant. The potential benefit of minimising blood loss on development of ROP will be investigated in a multicenter randomised trial (NCT04239690).

\section{INTRODUCTION}

Despite significant advances in neonatology during the last decades, the morbidity in extremely preterm and low birth weight preterm infants remains high. In Europe, $12 \%$ of infants born at 24-28 weeks of gestation developed severe retinopathy of prematurity (ROP) requiring treatment. ${ }^{1}$ Repeated adult red blood cell (RBC) transfusions in preterm infants are acknowledged risk factors for prematurityassociated diseases and constitute an independent predictor of adverse outcome, in particular for ROP and bronchopulmonary dysplasia (BPD). The current source of RBCs for transfusions to preterm infants is blood derived from adult donors. Fetal RBCs contain mainly fetal haemoglobin ( $\mathrm{HbF})$ which binds oxygen with greater affinity than adult haemoglobin $(\mathrm{HbA}){ }^{2}$ The fraction of $\mathrm{HbF}$ is approximately $70 \%-80 \%$ during the third pregnancy trimester with a gradual decrease to $3 \%-4 \%$ at 6 months after term age. ${ }^{3}$ In transfused newborns, $\mathrm{HbA}$ substitutes $\mathrm{HbF}$ during periods, while preterm erythropoiesis produces $\mathrm{RBC}$ with $\mathrm{HbF}$ at a postmenstrual age (PMA)-dependent rate. ${ }^{4}$ Both volume and number of RBCs transfusions are associated with increased ROP risk in infants with very and extremely $(\leq 1000 \mathrm{~g})$ low birth weight. ${ }^{5-7}$

Recent preliminary evidence suggests that a low fraction of $\mathrm{HbF}$ is an independent predictor for ROP in preterm neonates. ${ }^{8}$ Given the association between low $\mathrm{HbF}$ and ROP, it has been hypothesised that $\mathrm{HbF}$ per se might protect from oxidative stress. $^{8}{ }^{9}$ The decreased oxygen affinity of $\mathrm{HbA}$ results in increased availability of oxygen in the tissues of transfused compared with non-transfused extremely preterm infants and is therefore likely to contribute to hyperoxia ${ }^{2}$ and fluctuating oxygenation which are known risk factors for ROP. ${ }^{10}$ Other effects of $\mathrm{HbF}$ are largely unknown.

The relationship between administered blood transfusions and decreased fractions of $\mathrm{HbF}$ was shown recently in a relatively small cohort of very preterm infants. That study also indicated an association between lower fraction of $\mathrm{HbF}$ and the development of ROP. An underlying mechanism was proposed involving a shift of the oxygendissociation curve due to replacement of $\mathrm{HbF}$ by $\mathrm{HbA}$, resulting in a higher fraction of oxygen dissolved in plasma and increased exposure of tissue to oxygen. ${ }^{8}$

We hypothesised that early postnatal lower $\mathrm{HbF}$ is a risk factor for ROP. This was evaluated in 452 consecutively admitted inborn infants.

\section{MATERIAL AND METHODS}

\section{Patients and clinical characteristics}

This single-centre retrospective study included 452 live-born infants born before 30 weeks of gestational age (GA) at Skåne University Hospital in Lund, admitted to the neonatal intensive care unit (NICU), tertiary level, between 2009 and 2015. Infants were included, and data collected according to the ethical approval. GA was determined at 17-18 postmenstrual weeks by routine ultrasound fetometry. Birth weight (BW) small for GA (SGA) was defined as a BW $>2$ SD below the GA-related mean of the population according to the Swedish reference curve for normal fetal growth. ${ }^{11}$ During the study period, infants received supplemental oxygen aiming to achieve an $\mathrm{SpO}_{2}$ of $91 \%-95 \%$, when needed. Blood transfusions were administered to maintain $\mathrm{Hb}$ concentrations above $140 \mathrm{~g} / \mathrm{L}$ during the first postnatal week. ROP was classified 
according to the International Classification of Retinopathy of Prematurity ${ }^{12}$ and treatment followed recommended guidelines. ${ }^{13}$ Severe ROP was defined as stage 3 and/or type 1 ROP. Infants included in this cohort have previously been investigated when examining the role of $\mathrm{HbF}$ and the association to BPD. ${ }^{14}$ Efforts to minimise bias included continuous inclusion of all consecutively born infants during the study period, and a high frequency of infants with complete data. Ninety-eight of the included infants were part of a previous bi-centre study in Sweden investigating sampling-related blood volumes and blood transfusions. ${ }^{15}$

\section{Blood gas analyses}

In total, $11861 \mathrm{HbF}$ measurements were retrieved from clinical arterial blood gases obtained and analysed during the first 7 postnatal days (PNDs). Data on arterial HbF were retrieved from the local hard drive of the blood gas analyzer (Radiometer 800 , Copenhagen, Denmark) in the NICU. Arterial HbF analyses from each individual were sorted according to timepoint and date of analysis. Fraction of $\mathrm{HbF}(\%)$ of total $\mathrm{Hb}$ for each individual was calculated and averaged for each PND (1-7). Accumulated mean values for each day were then used when calculating a weekly mean of $\mathrm{HbF}$.

\section{Statistics}

Binary regression models assessed in the statistical analyses were verified in terms of multicollinearity; variance inflation factor score $>1,<10$, for linearity between the predictor and log-odds, independence of observations and outliers; Cook's distance $<1$ and leverage below a threshold level of $<3$ times $(k+1) / \mathrm{N}$. If any outlier was present, it was excluded and models rerun. Rerun analyses yielding non-similar results as compared with the original model were displayed if present. The mean of each blood gas variable during postnatal week 1 was used in logistic regression analysis. GA at birth, SGA and sex were assessed as independent confounding variables included in the full multiple variable analysis model. Infants with incomplete ROP data were excluded from the analysis. Inclusion of confounding variables in the model was based on clinical relationship to ROP development. Predicted probabilities were obtained by using logistic regression. Area under the curve (AUC) values using ROC analysis were used to evaluate independent predictive abilities. In all analyses, $\mathrm{p}$ values $<0.05$ were considered significant. For comparison between groups, independent samples t-test was used. When investigating thresholds of $\mathrm{HbF}(\%)$ and the development of ROP, quartiles were used, thus generating similar group sizes.

\section{RESULTS}

Overall, 452 live-born infants were included in the study with a mean (SD) GA of 26.4 (1.8) weeks and a mean (SD) birth weight of 876 (272) grams. The overall mortality rate prior to home discharge was $61 / 452(13.5 \%)$. Six (1.3\%) infants were lost to follow-up ROP screening at PMA 36 weeks. In total, 385 infants participated in the analyses and 104 (27\%) developed any and $37(9.6 \%)$ severe ROP. Clinical characteristics are shown in table 1 . The number of blood samples available for analysis on PNDs 1-7 were 1386, 2389, 2112, 1773, 1523, 1366 and 1312, respectively. The median (IQR) number of blood samples per subject and PND on PNDs 1-7 were 3 (2-4), 5 (3-7), 4 (3-7), 3 (2-6), 3 (1-5), $3(1-5)$ and $3(1-5)$. Mean values of $\mathrm{HbF}(\%)$ in relation to postnatal age (days) in infants without ROP and infants developing any ROP are displayed in figure 1.
Table 1 Clinical characteristics and blood gases per subject PND $1-7$

\begin{tabular}{ll}
\hline & $\begin{array}{l}\text { Infants with ROP outcome, } \\
\mathbf{n}=385\end{array}$ \\
\hline GA, weeks; mean (SD) & $26.6(1.7)$ \\
\hline Birth weight, g; mean (SD) & $900(261)$ \\
\hline BW SGA; $\mathrm{n}(\%)$ & $90(23.4)$ \\
\hline Male; $\mathrm{n}(\%)$ & $217(56.4)$ \\
\hline Twins; $\mathrm{n}(\%)$ & $87(22.6)$ \\
\hline Triplets; $\mathrm{n}(\%)$ & $18(4.7)$ \\
\hline Morbidities & \\
\hline IVH grades 3-4; $\mathrm{n}(\%)$ & $27(7.0)^{*}$ \\
\hline Any IVH; $\mathrm{n}(\%)$ & $96(25.1)^{*}$ \\
\hline NEC; $\mathrm{n}(\%)$ & $14(3.7)^{*}$ \\
\hline BPD; $\mathrm{n}(\%)$ & $212(55.9) \dagger$ \\
\hline
\end{tabular}

*383 available for analysis.

†379 available for analysis.

BPD, bronchopulmonary dysplasia; GA, gestational age; IVH, intraventricular haemorrhage; NEC, necrotising enterocolitis; PMA, postmenstrual age; PND, postnatal day; BW SGA, birth weight small for gestational age.

Infants with any ROP displayed significantly lower mean fractions of $\mathrm{HbF}(\%)$, during the first postnatal week, figure 2. Higher fraction of $\mathrm{HbF}(\%)$ during the first postnatal week was associated with a lower prevalence of any ROP, OR by a $10 \%$ increase 0.83 (95\% CI: 0.71 to $0.97 ; \mathrm{p}=0.019)$, following the adjustment for GA at birth, SGA and sex. The fraction of $\mathrm{HbF}$ (\%) was also inversely associated with severe ROP, both unadjusted ( $\mathrm{p}<0.001$ ), and in the full statistical model, OR by a $10 \%$ increase 0.79 (95\% CI: 0.63 to $0.99, \mathrm{p}=0.041)$.

When dividing the complete cohort in quartiles based on $\mathrm{HbF} \%$, the infants with an $\mathrm{HbF}(\%)$ in the lowest quartile had an OR of 22.0 (95\% CI: 8.1 to $59.2 ; \mathrm{p}<0.001)$ for developing any ROP, compared with infants an $\mathrm{HbF}$ in the highest quartile.

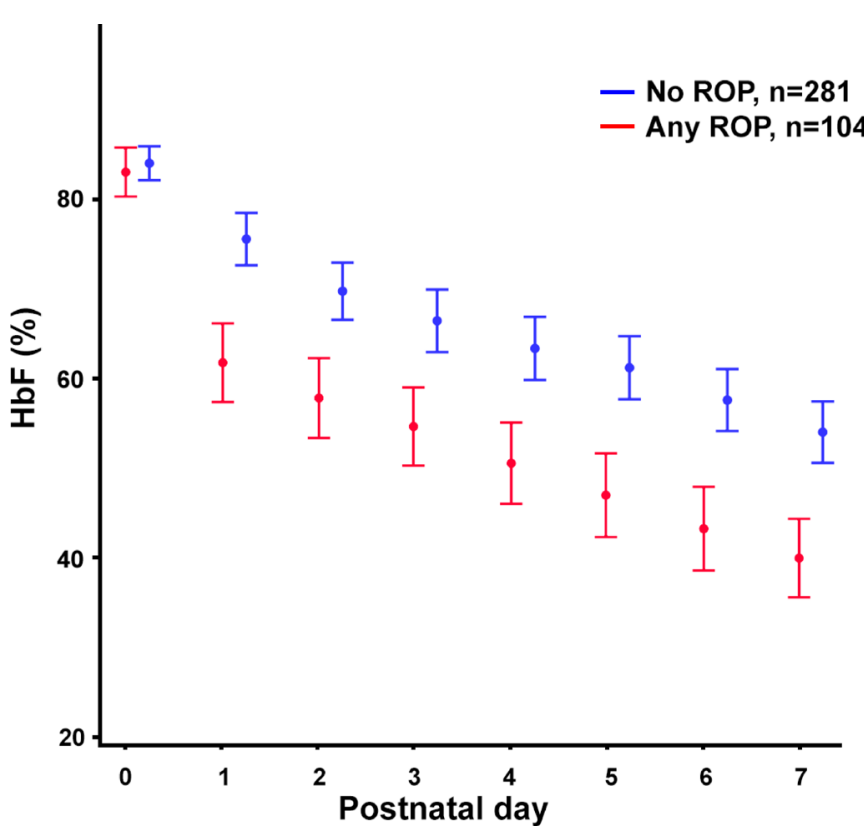

Figure 1 Mean fraction (\%) of $\mathrm{HbF}$ during postnatal days 1-7 in relation to development of any ROP. Infants with no ROP $(n=281)$ in blue; Infants with any ROP ( $n=104)$ in red. The bars represent $95 \% \mathrm{Cl}$. $\mathrm{HbF}$, fetal haemoglobin; ROP, retinopathy of prematurity. 


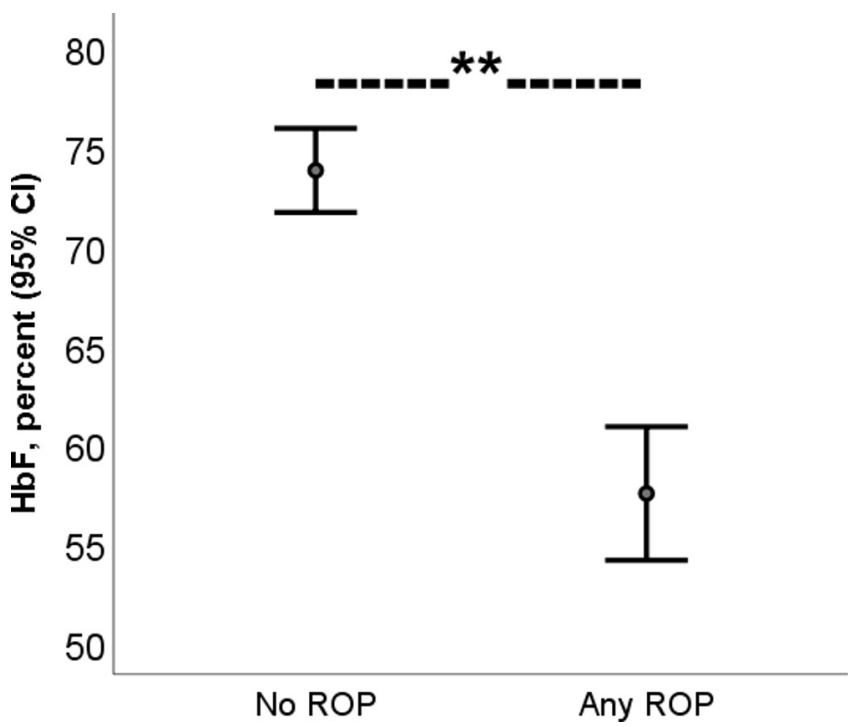

Figure 2 Significantly higher fraction of $\mathrm{HbF}$ during postnatal week 1 in infants without ROP compared with infants developing any ROP, in a cohort consisting of 452 very preterm infants. ${ }^{*}$ Indicating $\mathrm{p}<0.001$. $\mathrm{HbF}$, fetal haemoglobin; ROP, retinopathy of prematurity.

Estimated probability plots for ROP and mean $\mathrm{HbF}(\%)$ and for each quartile of $\mathrm{HbF}(\%)$ during postnatal week 1 considering GA at birth are illustrated in figure 3A,B.

The predictive ability (AUC) of $\mathrm{HbF}(\%)$ in the full model during the first week was 0.849 for any ROP, figure 4 .

\section{DISCUSSION}

The difference in fraction of HbF between infants who did or did not develop any ROP was pronounced the very first PND and persisted throughout the first postnatal week.

The probability of any ROP was inversely related to mean $\mathrm{HbF}$ during the first postnatal week, with a probability of near $60 \%$ for development of any ROP at a mean $\mathrm{HbF}$ of $40 \%$, compared with only a $10 \%$ probability at a mean $\mathrm{HbF}$ of $90 \%$. A similar pattern was also seen for severe ROP (data not shown). The potential causal mechanisms in ROP development involving low $\mathrm{HbF}$ thus appear to be operating during early postnatal development.
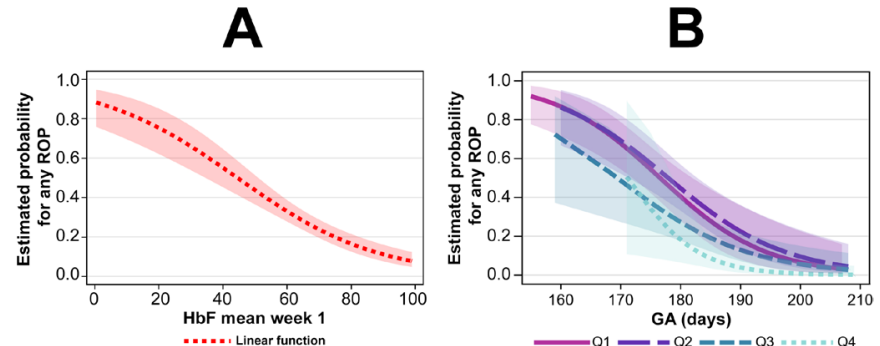

Figure $3(\mathrm{~A}, \mathrm{~B})$ Estimated probability for any ROP in relation to $\mathrm{HbF}$ (A) and GA at birth (B). Illustrated by linear function by mean $\mathrm{HbF}(\%)$ in postnatal week 1 in the complete cohort for any ROP (A) and by GA at birth illustrated per quartile of $\mathrm{HbF}(\%)$ in postnatal week 1 for any ROP (B). Q1 represents infants with a mean $\mathrm{HbF} \%$ in the lowest quartile in $\mathrm{B}$, and $\mathrm{Q} 4$ represent the infants with a mean $\mathrm{HbF} \%$ in the highest quartile. Q4; HbF\%>77.6\%, Q3; 74\%-77.6\%, Q2; 58.8\%-73.9\% and $\mathrm{Q} 1<58.8$. The shadowed area illustrates a $95 \% \mathrm{Cl}$. ROP, retinopathy of prematurity; $\mathrm{HbF}$, fetal haemoglobin; $\mathrm{GA}$, gestational age; Q, quartile.

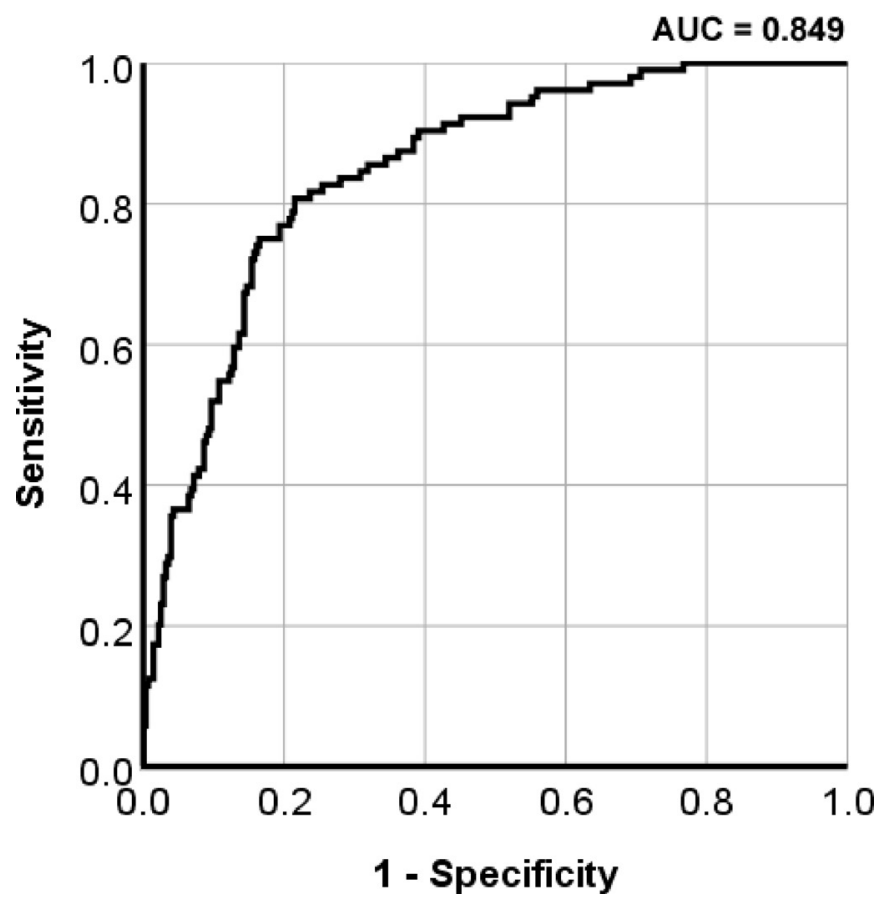

Figure 4 ROC curve for any ROP (A) and adjusted fraction of $\mathrm{HbF}(\%)$ during postnatal week 1. $\mathrm{HbF}(\%)$ adjusted for GA at birth, SGA and sex in the ROC curve. The AUC for HbF was 0.849. ROP, retinopathy of prematurity; $\mathrm{HbF}$, fetal haemoglobin; GA, gestational age; SGA, small for gestational age; AUC, area under the curve.

Importantly, the relationship between low $\mathrm{HbF}$ and later ROP reported here was independent of GA at birth and other potential confounders studied (SGA and sex). The probability for development of ROP also differed for the respective $\mathrm{HbF}$ quartiles across the range of GA at birth. The retina is part of the central nervous system and higher fractions of $\mathrm{HbF}$ in preterm infants have been shown to have beneficial effects in the brain such as increased oxygen transport, due to the specific oxygencarrying properties of $\mathrm{HbF}{ }^{16}$

It has been suggested that replacing $\mathrm{HbF}$ by $\mathrm{HbA}$, thus lowering $\mathrm{HbF}$ levels may lead to high oxygen exposure to the developing retina thereby increasing the risk of acute ROP. ${ }^{8} 17$

Studies in animals and humans receiving repeated intrauterine transfusions found that $\mathrm{HbA}$ retains its low oxygen binding properties also in the fetal circulation. ${ }^{18}$ Notably, as compared with $\mathrm{HbA}, \mathrm{HbF}$ has a greater capacity to generate nitric oxide (which plays an important role in regulating tone and blood flow), ${ }^{19}$ and is less prone to the DNA cleavage activity, ${ }^{20} \mathrm{HbF}$ seems to protect from reactive oxygen species. ${ }^{21}$ On the other hand, birth is accompanied by oxidative stress and cord blood contains more non protein bound iron and its erythrocytes have higher membrane esterified F2-isoprostane levels and increased superoxide anion production than adult erythrocytes $^{22}$ and, in addition, low levels of antioxidants. ${ }^{23}$ Based on all the above-mentioned considerations, we hypothesised that fetal RBCs containing $\mathrm{HbF}$ might be more physiologically relevant than RBCs from adults containing $\mathrm{HbA}$ in relation to ROP development.

The association between low $\mathrm{HbF}$ proportion and later ROP and changes in $\mathrm{HbF}$ might also reflect the loss of other endogenous blood components essential for normal organ development. A main contributor to anaemia in very preterm infants is excessive blood sampling. A significant reduction in iatrogenic blood 
loss in very preterm infants might maintain circulating growth factors, thereby improving the outcome of these infants. ${ }^{24}$ The concentration of circulating haematopoietic stem cells is inversely related to GA at birth. ${ }^{25}$ Historically, blood transfusions have been used as therapy for apnea and bradycardia, poor feeding, poor weight gain, and pallor. Although many studies have examined these outcomes, few are methodologically sound. ${ }^{26}$ A recent report from a Swedish national population-based cohort showed that extremely preterm infants receive a mean of seven adult blood transfusions per infant during the neonatal period with a considerable between-centre variation (three to nine transfusions per infant). ${ }^{27}$ Guidelines at Swedish units use reference values of haemoglobin $(\mathrm{g} / \mathrm{l})$ at different postnatal ages as markers of need of transfusion.

Delayed cord clamping at birth is by far the most favourable intervention for preventing anaemia. As shown in a Cochrane meta-analysis, the resulting autotransfusion of fetoplacental blood, reduces the number of blood transfusions and decreases rate of intraventricular haemorrhage and necrotising enterocolitis in very preterm infants. ${ }^{26}$ The impressive effects of delayed cord clamping strongly supports the hypothesis that fetal blood components are essential for prevention of morbidity in the extremely preterm infant. The excessive decrease in $\mathrm{HbF}$ observed during the first postnatal week is to a large extent reflecting current blood sampling strategies and existing laboratory infrastructures for blood sample analysis. It was recently shown that sample-related blood loss during neonatal clinical care is linked to the number of administered blood transfusions. ${ }^{15}$ The study showed a median sample-related withdrawal of whole blood of $58 \%$ of total blood volume $(42 \mathrm{~mL} / \mathrm{kg})$ during the first two postnatal weeks and a median transfused volume of more than $100 \%$ of total blood volume $(85 \mathrm{~mL} / \mathrm{kg})$ with adult donor blood during the corresponding period.

This finding emphasises the importance of developing and implementing blood-saving sampling methodology in the clinical care of very preterm infants. Recently a multicenter study was initiated with the aim to study the impact of microsampling to preserve $\mathrm{HbF}$ and thereby reduce neonatal morbidities including ROP, www.clinicaltrials.gov \#NCT04239690.

As previously mentioned, decreased fraction of $\mathrm{HbF}$ is highly correlated with the volume of administered blood from adult donors. Several studies have shown associations between administered blood transfusions and increased rates of neonatal morbidity. However, prospective studies comparing liberal or restrictive transfusion strategies based on differing $\mathrm{Hb}$ thresholds have not, as yet, been able to show a clear impact on either short-term or long-term morbidity. ${ }^{2829}$

Regarding whether the pathophysiological mechanisms associated with our present finding of low HbF being associated with higher risk of abnormal retinal neurovascular development is low $\mathrm{HbF}$ itself, or a proxy of reduction in other endogenous fetal blood components, or adult transfusions, or a combination cannot at this stage be elucidated. In a recent publication aiming to titrate out the risk of early anaemia versus transfusions for ROP development, it was suggested that early anaemia, rather than blood transfusions, was a risk factor for ROP warranting treatment. ${ }^{30}$ Further, although the degree of immaturity, SGA and sex were adjusted for, sicker infants are more prone to a more frequent blood sampling rate.

This study has a number of limitations, one of which is its retrospective design. This study included all consecutively admitted infants born before 30 gestational weeks from 2009 to 2015. The data from this single-centre study reflect the medical routines and regimes at one NICU (Swedish level III). This study population, consisting of very preterm infants, is heterogenous due to the high frequencies of morbidities, clinical interventions, and the integration of new clinical routines. Priorly, an in-depth analysis of the local sampling regimes have been illustrated, based on a subcohort of this study population. ${ }^{15}$

The main strength of this study is the high intensity of data points and high number of retrieved blood gas analyses along with the size of the study. By using the same blood gas analyser during the study period, data on $\mathrm{HbF}$ was downloadable directly from the analyser's hard disk, the risk of errors was minimised.

\section{CONCLUSION}

Low fraction of $\mathrm{HbF}$ during the first postnatal week was independently associated with the development of any and severe ROP in very preterm infants. Conversely, maintaining a higher percentage of $\mathrm{HbF}$ may be protective for developing ROP. The potential beneficial role of minimising the loss of endogenous blood components in a clinical setting will be further investigated in an ongoing multicenter randomised trial.

Acknowledgements We thank Petter Blomqvist, Johan Sandblom, Anna-Lena Hård, statistician Aldina Pivodic, MSc in mathematics, the research nurses and the staff at the Neonatal Intensive Care Unit in Lund and Malmö for valuable assistance.

Contributors All authors made substantial contributions to the conception and design, acquisition of data, and/or analysis and interpretation of data in this study. WH and DL performed the statistical analysis, drafted the initial manuscript and designed the figures. All authors contributed to the writing of the article and revising it critically for important intellectual content and approved the final version for publication.

Funding This study was supported by the Swedish Research Council (201601131, 2017-02112, and 2018-0070), ALF Government grants to Lund University and Skåne University Hospital (ALF-44001) and Sahlgrenska University Hospital (ALFGBG-717971, ALFGBG-812951), The Skåne Council Foundation for research (grant number not applicable), The Gothenburg Medical Society (grant number not applicable), De Blindas Vänner (grant number not applicable) and The Wallenberg Clinical Scholars (grant number not applicable).

Competing interests None declared.

Patient consent for publication Not required.

Ethics approval Patient consent was obtained. Ethical approval number: D:nr 197/2006 (decision 2006-06-01) and D:nr 2009/190 (decision 2009-06-11).

Provenance and peer review Not commissioned; externally peer reviewed.

Data availability statement Data are available upon reasonable request. Deidentified data will be available on reasonable request.

Open access This is an open access article distributed in accordance with the Creative Commons Attribution Non Commercial (CC BY-NC 4.0) license, which permits others to distribute, remix, adapt, build upon this work non-commercially, and license their derivative works on different terms, provided the original work is properly cited, appropriate credit is given, any changes made indicated, and the use is non-commercial. See: http://creativecommons.org/licenses/by-nc/4.0/.

\section{ORCID iDs}

William Hellström http://orcid.org/0000-0001-6669-260X

Lotta Gränse http://orcid.org/0000-0003-4425-9033

Ann Hellström http://orcid.org/0000-0002-9259-1244

\section{REFERENCES}

1 Vermont Oxford database Secondary Vermont Oxford database, 2019. Available: https://public.vtoxford.org/

2 De Halleux V, Truttmann A, Gagnon C, et al. The effect of blood transfusion on the hemoglobin oxygen dissociation curve of very early preterm infants during the first week of life. Semin Perinatol 2002;26:411-5.

3 Watanabe H, Shitara Y, Aoki Y, et al. Hemoglobin phase of oxygenation and deoxygenation in early brain development measured using fNIRS. Proc Natl Acad Sci U SA 2017;114:E1737-44. doi:10.1073/pnas.1616866114

4 Bard $\mathrm{H}$, Widness JA. The life span of erythrocytes transfused to preterm infants. Pediatr Res 1997;42:9-11. doi:10.1203/00006450-199707000-00002

5 Lust $C$, Vesoulis Z, Jackups $R$, et al. Early red cell transfusion is associated with development of severe retinopathy of prematurity. J Perinatol 2019;39:393-400. doi:10.1038/s41372-018-0274-9 
6 Wang Y-C, Chan O-W, Chiang M-C, et al. Red blood cell transfusion and clinical outcomes in extremely low birth weight preterm infants. Pediatr Neonatol 2017:58:216-22. doi:10.1016/j.pedneo.2016.03.009

7 Dani C, Reali MF, Bertini G, et al. The role of blood transfusions and iron intake on retinopathy of prematurity. Early Hum Dev 2001;62:57-63.

8 Stutchfield CJ, Jain A, Odd D, et al. Foetal haemoglobin, blood transfusion, and retinopathy of prematurity in very preterm infants: a pilot prospective cohort study. Eye 2017:31:1451-5. doi:10.1038/eye.2017.76

9 Teofili L, Bianchi M, Baldascino A, et al. Foetal haemoglobin, blood transfusion, and retinopathy of prematurity. Eye 2018;32:1155-6. doi:10.1038/s41433-0180030-6

10 Das A, Mhanna M, Sears J, et al. Effect of fluctuation of oxygenation and time spent in the target range on retinopathy of prematurity in extremely low birth weight infants. J Neonatal Perinatal Med 2018;11:257-63. doi:10.3233/NPM-1757

11 Marsál K, Persson PH, Larsen T, et al. Intrauterine growth curves based on ultrasonically estimated foetal weights. Acta Paediatr 1996;85:843-8. doi:10.1111/j.1651-2227.1996.tb14164.x

12 Molinari A, Weaver D, Jalali S. Classifying retinopathy of prematurity. Community Eye Health 2017:30:55-6.

13 Hardy RJ, Good WV, Dobson V, et al. The early treatment for retinopathy of prematurity clinical trial: presentation by subgroups versus analysis within subgroups. $\mathrm{Br} J$ Ophthalmol 2006;90:1341-2. doi:10.1136/bjo.2006.102038

14 Hellström W, Martinsson T, Hellstrom A, et al. Fetal haemoglobin and bronchopulmonary dysplasia in neonates: an observational study. Arch Dis Child Fetal Neonatal Ed 2021;106:88-92. doi:10.1136/archdischild-2020-319181

15 Hellström W, Forssell L, Morsing E, et al. Neonatal clinical blood sampling led to major blood loss and was associated with bronchopulmonary dysplasia. Acta Paediatr 2020;109:679-87. doi:10.1111/apa.15003

16 Ramaekers VT, Daniels H, Casaer P. Brain oxygen transport related to levels of fetal haemoglobin in stable preterm infants. J Dev Physiol 1992;17:209-13.

17 Jiramongkolchai K, Repka MX, Tian J, et al. Lower foetal haemoglobin levels at 31and 34-weeks post menstrual age is associated with the development of retinopathy of prematurity : PaclFiHER Report No. 1 PaclFiHER Study Group (Preterm Infants and Fetal Haemoglobin in ROP). Eye 2020. doi:10.1038/s41433-020-0938-5. [Epub ahead of print: 14 May 2020].

18 Novy MJ, Frigoletto FD, Easterday CL, et al. Changes in umbilical-cord blood oxygen affinity after intrauterine transfusions for erythroblastosis. N Eng/ J Med 1971;285:589-95. doi:10.1056/NEJM197109092851101
19 Salhany JM. The oxidative denitrosylation mechanism and nitric oxide release from human fetal and adult hemoglobin, an experimentally based model simulation study. Blood Cells Mol Dis 2013;50:8-19. doi:10.1016/j.bcmd.2012.08.006

20 Chakane S, Matos T, Kettisen K, et al. Fetal hemoglobin is much less prone to DNA cleavage compared to the adult protein. Redox Biol 2017;12:114-20. doi:10.1016/j. redox.2017.02.008

21 Ratanasopa K, Strader MB, Alayash Al, et al. Dissection of the radical reactions linked to fetal hemoglobin reveals enhanced pseudoperoxidase activity. Front Physiol 2015;6:39. doi:10.3389/fphys.2015.00039

22 Rossi V, Leoncini S, Signorini C, et al. Oxidative stress and autologous immunoglobulin $\mathrm{G}$ binding to band 3 dimers in newborn erythrocytes. Free Radic Biol Med 2006;40:907-15. doi:10.1016/j.freeradbiomed.2005.11.021

23 Bracci R, Perrone S, Buonocore G. Oxidant injury in neonatal erythrocytes during the perinatal period. Acta Paediatr Supp/ 2002;91:130-4

24 Katsimpardi L, Litterman NK, Schein PA, et al. Vascular and neurogenic rejuvenation of the aging mouse brain by young systemic factors. Science 2014;344:630-4. doi:10.1126/science. 1251141

25 Podestà M, Bruschettini M, Cossu C, et al. Preterm cord blood contains a higher proportion of immature hematopoietic progenitors compared to term samples. PLoS One 2015;10:e0138680. doi:10.1371/journal.pone.0138680

26 Rabe H, Diaz-Rossello JL, Duley L, et al. Effect of timing of umbilical cord clamping and other strategies to influence placental transfusion at preterm birth on maternal and infant outcomes. Cochrane Database Syst Rev 2012:CD003248. doi:10.1002/14651858.CD003248.pub3

27 Svenskt neonatalt kvalitetsregister (SNQ) Årsrapport 2016. Secondary Svenskt neonatalt kvalitetsregister (SNQ) Årsrapport 2016 2016. Available: https://www. medscinet.com/pnq/Uploads/Årsrapport\%20SNQ\%202016_2.pdf

28 Franz AR, Engel C, Bassler D, et al. Effects of liberal vs restrictive transfusion thresholds on survival and neurocognitive outcomes in extremely low-birth-weight infants: the ETTNO randomized clinical trial. JAMA 2020;324:560-70. doi:10.1001/ jama.2020.10690

29 Whyte R, Kirpalani H. Low versus high haemoglobin concentration threshold for blood transfusion for preventing morbidity and mortality in very low birth weight infants. Cochrane Database Syst Rev 2011;11:CD000512. doi:10.1002/14651858. CD000512.pub2

30 Lundgren $\mathrm{P}$, Athikarisamy SE, Patole $\mathrm{S}$, et al. Duration of anaemia during the first week of life is an independent risk factor for retinopathy of prematurity. Acta Paediatr 2018;107:759-66. doi:10.1111/apa.14187 